\title{
Efficacy and safety of bazedoxifene for postmenopausal osteoporosis
}

This article was published in the following Dove Press journal:

Clinical Interventions in Aging

20 June 2011

Number of times this article has been viewed

\section{Hisaya Kawate \\ Ryoichi Takayanagi}

Department of Medicine and Bioregulatory Science, Graduate School of Medical Sciences, Kyushu University, Fukuoka, Japan
Correspondence: Hisaya Kawate Department of Medicine and

Bioregulatory Science, Graduate School of Medical Sciences, Kyushu University,

3-I-I Maidashi, Higashi-ku,

Fukuoka 812-8582, Japan

$\mathrm{Tel}+8 \mathrm{I} 926425280$

Fax +8I 926425287

Email kawate@intmed3.med.kyushu-u.ac.jp
Abstract: Bazedoxifene, a novel selective estrogen receptor modulator, has been developed to have favorable effects on bone and the lipid profile while minimizing stimulation of uterine or breast tissues. Two large Phase III clinical trials showed that bazedoxifene, as well as raloxifene, increased bone mineral density, decreased levels of bone turnover markers, and significantly reduced the risk of new vertebral fractures in postmenopausal women compared with placebo. Although the incidence of nonvertebral fractures with bazedoxifene or raloxifene did not differ significantly from that with placebo, a post hoc analysis of a subgroup of women at higher fracture risk revealed that bazedoxifene significantly reduced the nonvertebral fracture risk relative to placebo and raloxifene. Bazedoxifene also improved the lipid profile by reducing the serum concentrations of total cholesterol and low-density lipoprotein cholesterol, with an increase in the serum level of high-density lipoprotein cholesterol. The incidences of vasodilatation (hot flushes), leg cramps, and venous thromboembolic events were significantly higher with bazedoxifene and raloxifene compared with placebo. There was no evidence of endometrial and breast stimulation with bazedoxifene. Taking advantage of the favorable effects of bazedoxifene on the breast and endometrium, the pairing of bazedoxifene with conjugated estrogens is under investigation for the treatment of menopausal symptoms and prevention of postmenopausal osteoporosis. A Phase III trial showed that combination therapy of bazedoxifene and conjugated estrogens significantly increased bone mineral density and decreased bone turnover markers, with relief of hot flushes and improvement of vaginal atrophy. This article reviews the clinical efficacy and safety of bazedoxifene in the treatment of postmenopausal osteoporosis.

Keywords: selective estrogen receptor modulators, osteoporosis, estrogen receptor, nonvertebral fracture, endometrium

\section{Introduction}

Osteoporosis is a systemic skeletal disease characterized by loss of bone mass and strength, which leads to bone fragility and increased susceptibility to fractures. ${ }^{1,2}$ Osteoporotic fractures, which usually occur at the spine, hip, and distal radius, impact negatively on quality of life and increase both morbidity and mortality. ${ }^{3-6}$ Health care costs for patients with osteoporotic fractures are anticipated to rise in parallel with the increase in elderly populations. Treatment of osteoporotic patients is important for both preventing osteoporotic fractures and reducing the associated health care burden.

Declining levels of endogenous estrogens mainly contribute to rapid bone loss at the time of menopause, leading to postmenopausal osteoporosis. It has been demonstrated that long-term hormone replacement therapy with estrogen plus progestin prevents bone loss and fractures. ${ }^{7,8}$ However, large randomized controlled trials had 
suggested that hormone replacement therapy increased the risk of breast cancer, although they have demonstrated that hormone replacement therapy significantly reduced the risk of osteoporotic fractures. ${ }^{9}$ To avoid such negative aspects of estrogen action, selective estrogen receptor modulators (SERMs), which act as estrogen receptor agonists in some tissues and as estrogen receptor antagonists in others, have been developed (Figure 1). An ideal SERM would have beneficial agonistic effects on bone, the cardiovascular system, and the central nervous system to prevent bone loss and cardiovascular events, but have anti-estrogenic effects on the breast and endometrium to reduce the risk of breast and endometrial cancers.

Tamoxifen was the first SERM used clinically to reduce the risk of breast cancer in high-risk women. ${ }^{10,11}$ It was also reported that tamoxifen maintained bone mineral density in postmenopausal women. ${ }^{12}$ However, long-term treatment with tamoxifen increased the risks of endometrial cancer and blood clots, related to the partial estrogen receptor agonistic activity of this compound. ${ }^{13}$ Raloxifene was also found to be an effective estrogen receptor antagonist against breast cancer. In addition to its lack of proliferative effects on the uterus, unlike tamoxifen, raloxifene was shown to decrease plasma cholesterol levels and prevent decreases in bone mineral density. ${ }^{14}$ Raloxifene acts as an estrogen agonist in bone and lipid metabolism but an estrogen antagonist in the breast. Raloxifene is the first SERM to have been approved by the US Food and Drug Administration for the prevention and treatment of postmenopausal osteoporosis. ${ }^{15,16}$

Bazedoxifene is a third-generation SERM, which was recently approved for the treatment of postmenopausal osteoporosis in Europe and Japan. This comprehensive review describes the efficacy and safety of bazedoxifene in patients with osteoporosis.

\section{Bazedoxifene}

Bazedoxifene acetate (WAY-140424, TSE-424) is an indole-based estrogen receptor ligand with unique structural characteristics (Figure 1). The molecule was assembled by using raloxifene as a template and substituting an indole ring for the benzothioprine core. ${ }^{17,18}$ To select this novel SERM, a stringent selection process was implemented to assess its biological activity and tissue selectivity on key endpoints, which included the uterus, lipid metabolism, bone remodeling, and central nervous system function. ${ }^{19-21}$

\section{Preclinical research In vitro studies}

Bazedoxifene binds to both estrogen receptor alpha $(E R \alpha)$ and estrogen receptor beta $(\mathrm{ER} \beta)$, with $\mathrm{IC}_{50}$ values of $23 \pm 15 \mathrm{nM}$<smiles>C[C@]12CCC3c4ccc(O)cc4CCC3C1CC2</smiles>

$17 \beta$-estradiol
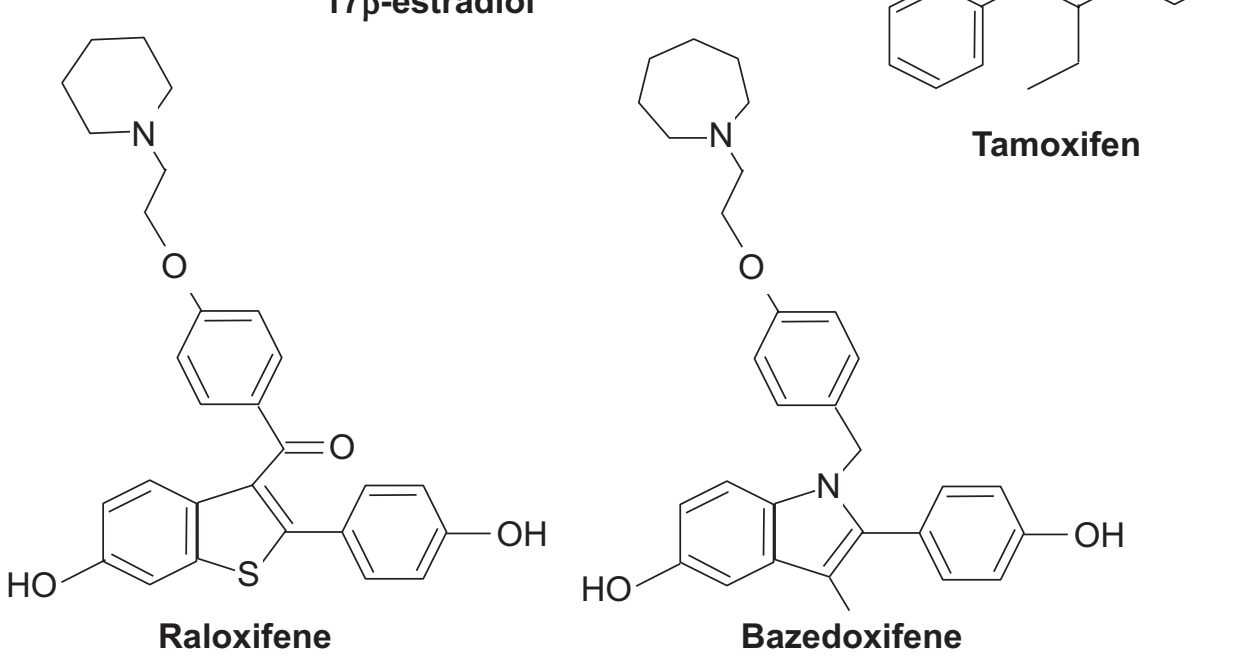

Figure I Chemical structures of $17 \beta$-estradiol and selective estrogen receptor modulators.

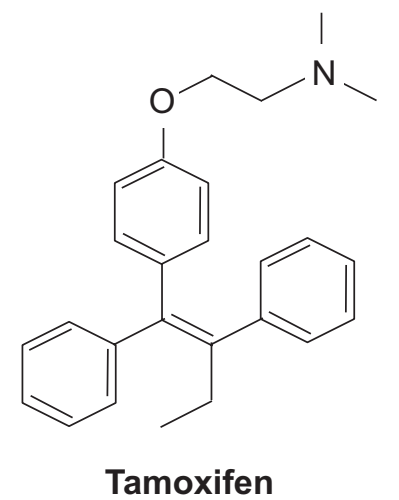


and $85 \pm 59 \mathrm{nM}$, respectively, and a slight preference for $E R \alpha .{ }^{19,21}$ Its affinity for ER $\alpha$ is about 10 -fold lower than that of $17 \beta$-estradiol $\left(\mathrm{IC}_{50} 3 \pm 1 \mathrm{nM}\right)$ and raloxifene $\left(\mathrm{IC}_{50}\right.$ $4 \pm 3 \mathrm{nM}$ ). Bazedoxifene competitively inhibits $17 \beta$-estradiol binding to both $\mathrm{ER} \alpha$ (dissociation constant for bazedoxifene $0.1 \mathrm{nM})$ and $\operatorname{ER} \beta(0.3 \mathrm{nM})$. In MCF-7 breast cancer cells, bazedoxifene showed no estrogen receptor agonist activity, but inhibited $17 \beta$-estradiol-induced transcriptional activation. ${ }^{19,21}$ Bazedoxifene did not stimulate the proliferation of MCF-7 cells, but did inhibit $17 \beta$-estradiol-induced proliferation in a dose-dependent manner. ${ }^{19,21}$

\section{Effects on bone}

In a 6-week ovariectomized rat model, bazedoxifene $0.3 \mathrm{mg} / \mathrm{kg} /$ day consistently and significantly increased bone mass compared with control animals. ${ }^{19,21}$ The vertebral compressive strength in bazedoxifene-treated ovariectomized rats was equivalent to or better than that in sham-operated animals and significantly better than that in vehicle-treated ovariectomized animals. ${ }^{21}$ Bone histology was also maintained in bazedoxifene-treated ovariectomized rats.

\section{Endometrial effects}

In an immature rat uterine model, ethinyl estradiol increased the wet uterine weight after 3 days of treatment. Bazedoxifene $0.5 \mathrm{mg} / \mathrm{kg}$ and $5.0 \mathrm{mg} / \mathrm{kg}$ was associated with a smaller increase in wet uterine weight than either ethinyl estradiol or raloxifene. ${ }^{21}$ Histological examination revealed that bazedoxifene did not cause luminal epithelial cell hypertrophy or hyperplasia, myometrial hypertrophy, or luminal distention. Cotreatment of bazedoxifene and raloxifene completely abrogated stimulation of luminal epithelial cells and the myometrium by raloxifene, supporting an improved uterine profile for bazedoxifene. ${ }^{21}$ Anti-estrogenic effects of bazedoxifene on the endometrium were also confirmed in an ovariectomized mouse model. ${ }^{22}$

\section{Vasomotor effects}

In a morphine-addicted rat model of vasomotor activity, naloxone injection resulted in a rapid rise in tail skin temperature. The increase in tail skin temperature was abrogated in rats pretreated with estrogen receptor agonists. Similar to raloxifene, bazedoxifene did not act as an estrogen receptor agonist in this model. When a bone-sparing dose $(0.3 \mathrm{mg} / \mathrm{kg} /$ day $)$ of bazedoxifene was coadministered with ethinyl estradiol, no antagonism was detected, which may indicate a potential lack of a vasomotor effect of bazedoxifene in postmenopausal women. ${ }^{21}$

\section{Mammary glands}

In a study comparing the relative effects of SERMs on the mammary gland of ovariectomized mice, bazedoxifene exhibited less agonist activity and was a more effective antagonist of conjugated estrogens in the mammary gland than other SERMs, ie, raloxifene and lasofoxifene, as assessed by both gene expression and morphology of the mammary gland. ${ }^{22}$

\section{Lipid profiles}

In a 6-week ovariectomized rat study, bazedoxifene significantly reduced total cholesterol level as effectively as raloxifene. ${ }^{19,21}$

\section{Clinical studies}

\section{Clinical pharmacokinetics and metabolism}

In a Phase I dose-proportionality study in healthy postmenopausal women, bazedoxifene reached a maximum plasma concentration at 1-2 hours after oral administration, and its half-life was approximately 28 hours. A steady-state plasma concentration was achieved by day 7 , and linear pharmacokinetics were observed in the dose range tested (5-40 mg). ${ }^{23}$ The metabolic profile of bazedoxifene was analyzed using a single oral dose of $\left[{ }^{14} \mathrm{C}\right]$ bazedoxifene $20 \mathrm{mg}$. The major route of excretion was the feces (84.7\%), with less than $1 \%$ excreted in the urine. The predominant metabolite was bazedoxifene-5-glucuronide (40\%-95\%). ${ }^{24}$ There was little or no cytochrome P450-mediated metabolism of bazedoxifene.

\section{Phase II clinical efficacy and safety}

A 3-month, randomized, placebo-controlled study demonstrated that bazedoxifene reduced bone turnover markers in healthy menopausal women $(\mathrm{n}=494)$ in a dose-dependent manner. ${ }^{25}$ A 6-month, double-blind, randomized study of healthy postmenopausal women $(n=497)$ assessed the endometrial effects of bazedoxifene. ${ }^{26}$ No significant differences in endometrial thickness were observed from baseline for bazedoxifene doses of 2.5-20 mg/day. On the other hand, significant decreases in endometrial thickness and decreased uterine bleeding were observed for bazedoxifene doses of $30 \mathrm{mg}$ and $40 \mathrm{mg}$ compared with placebo. ${ }^{26}$ The incidence of breast pain was also significantly lower in the bazedoxifene $40 \mathrm{mg}$ group than in the placebo group. ${ }^{27}$

\section{Phase III clinical trials}

Two large, prospective, global Phase III trials of bazedoxifene for osteoporosis prevention and treatment have been 
completed. ${ }^{28,29}$ Both studies were randomized, doubleblind trials and included a placebo and a positive control (raloxifene).

\section{Two-year Phase III study}

In a 2-year Phase III study, a total of 1583 healthy postmenopausal women with a bone mineral density $\mathrm{T}$ score at the lumbar spine or femoral neck between -1.0 and -2.5 or clinical risk factors for osteoporosis were randomly assigned to one of five groups, ie, bazedoxifene 10, 20, or $40 \mathrm{mg} /$ day, placebo, or raloxifene $60 \mathrm{mg} / \mathrm{day}^{28}$ All the women received daily supplementation with elemental calcium $600 \mathrm{mg}$. Compared with placebo, all doses of bazedoxifene and raloxifene prevented bone loss at all skeletal sites. The mean differences in percent change in lumbar spine bone density from baseline to 24 months relative to placebo were $1.08 \% \pm 0.28 \%, 1.41 \% \pm$ $0.28 \%$, and $1.49 \% \pm 0.28 \%$ for bazedoxifene 10,20 , and $40 \mathrm{mg}$, respectively ( $P<0.001$ for all comparisons). All the bazedoxifene treatment groups had significantly greater bone mineral density at the total hip in comparison with the placebo group at 6, 12, 18, and 24 months. Significant reductions in serum levels of osteocalcin and cross-linked C-terminal telopeptide of type I collagen from baseline and relative to placebo were observed for all doses of bazedoxifene and raloxifene treatment as early as 3 months, and were sustained until the end of the study $(P<0.001)$. Serum concentrations of total cholesterol and low-density lipoprotein cholesterol were decreased with bazedoxifene and raloxifene treatment compared with placebo, whereas serum levels of high-density lipoprotein cholesterol were elevated after treatment with the SERMs. Although significant increases from baseline in the median concentrations of triglycerides were observed among women receiving bazedoxifene $20 \mathrm{mg}$ and $40 \mathrm{mg}$ and placebo, there were no significant differences between the groups. The overall incidences of adverse events, serious adverse events, and discontinuations caused by adverse events were similar among the groups (Table 1). The most common adverse events included headache, infection, arthralgia, pain, hot flushes, and back pain. ${ }^{28}$

\section{Three-year Phase III study}

In a 3-year Phase III study, 7492 healthy postmenopausal women aged 55-85 years with osteoporosis, defined by low bone mineral density or radiographically confirmed vertebral fractures, were randomized to treatment with bazedoxifene 20 or $40 \mathrm{mg} /$ day, raloxifene $60 \mathrm{mg} /$ day, or placebo. ${ }^{29}$ All the subjects received daily oral calcium $\leq 1200 \mathrm{mg}$ and vitamin D 400-800 IU supplementation. The primary endpoint was the incidence of new vertebral fractures after 36 months and secondary endpoints included nonvertebral fractures, bone mineral density, and bone turnover markers. Treatment with bazedoxifene 20 and $40 \mathrm{mg}$ and raloxifene $60 \mathrm{mg}$ significantly increased lumbar spine and total hip bone mineral density (Figure 2) and reduced serum levels of osteocalcin and C-terminal telopeptide of type I collagen compared with placebo. Among 6847 subjects in the intention-to-treat population, the incidence of new vertebral fractures was significantly lower $(P<0.05)$ for bazedoxifene $20 \mathrm{mg}(2.3 \%)$, bazedoxifene $40 \mathrm{mg}(2.5 \%)$, and raloxifene $60 \mathrm{mg}(2.3 \%)$ compared with placebo (4.1\%). Relative to

Table I Safety profile of bazedoxifene in two Phase III trials

\begin{tabular}{|c|c|c|c|c|c|c|}
\hline \multirow[b]{2}{*}{ Adverse event, n (\%) } & \multicolumn{3}{|l|}{ 2-year study ${ }^{28}$} & \multicolumn{3}{|l|}{ 3-year study ${ }^{29}$} \\
\hline & $\begin{array}{l}\text { Bazedoxifene }^{a} \\
(n=962)\end{array}$ & $\begin{array}{l}\text { Raloxifene } \\
(n=3 I I)\end{array}$ & $\begin{array}{l}\text { Placebo } \\
(n=3 \mid 0)\end{array}$ & $\begin{array}{l}\text { Bazedoxifene } \\
(n=3758)\end{array}$ & $\begin{array}{l}\text { Raloxifene } \\
(n=1849)\end{array}$ & $\begin{array}{l}\text { Placebo } \\
(n=1885)\end{array}$ \\
\hline Any adverse event & $916(95.2)$ & $309(96.0)$ & $297(95.8)$ & 3598 (95.7) & $1775(96.0)$ & $1813(96.2)$ \\
\hline Any serious adverse event & $99(10.3)$ & $29(9.3)$ & $28(9.0)$ & $750(20.0)$ & $344(18.6)$ & $353(18.7)$ \\
\hline Discontinuations caused by $\mathrm{AE}$ & 167 (17.4) & $43(13.8)$ & $48(15.5)$ & $539(14.3)$ & $262(14.2)$ & $240(12.7)$ \\
\hline \multicolumn{7}{|l|}{ Selected adverse events } \\
\hline Myocardial infarction & $3(0.3)$ & 0 & I (0.3) & $16(0.4)$ & $6(0.3)$ & $8(0.4)$ \\
\hline Strokes & $2(0.2)$ & I (0.3) & 0 & $38(1.0)$ & $15(0.8)$ & $20(I . I)$ \\
\hline Deep vein thrombosis & $2(0.2)$ & 0 & $\mathrm{I}(0.3)$ & $18(0.5)$ & $8(0.4)$ & $\mathrm{I}(0 . \mathrm{I})$ \\
\hline Pulmonary embolus & I (0.I) & 0 & 0 & $8(0.2)$ & $4(0.2)$ & $4(0.2)$ \\
\hline Retinal vein thrombosis & 0 & $\mathrm{I}(0.3)$ & 0 & $3(0.1)$ & 0 & $3(0.2)$ \\
\hline Hot flushes & $207(21.5)$ & $58(18.6)$ & $44(14.2)$ & 481 (12.8) & $222(12.0)$ & $118(6.3)$ \\
\hline Leg cramps & 107 (I I.I) & 37 (1 I.9) & $36(11.6)$ & 409 (10.9) & $216(11.7)$ & $155(8.2)$ \\
\hline Endometrial carcinoma & 0 & 0 & $\mathrm{I}(0.3)$ & $2(0.05)$ & $2(0.1)$ & $3(0.2)$ \\
\hline Endometrial hyperplasia & 0 & 0 & 0 & $2(0.05)$ & $\mathrm{I}(0.1)$ & $I(0.1)$ \\
\hline Breast carcinoma & $3(0.3)$ & I (0.3) & $2(0.6)$ & $9(0.2)$ & $7(0.4)$ & $8(0.4)$ \\
\hline
\end{tabular}

Notes: ${ }^{\mathrm{a} T}$ Total number of subjects who received bazedoxifene 10, 20, or $40 \mathrm{mg} /$ day; ${ }^{\mathrm{b} T o t a l}$ number of subjects who received bazedoxifene 20 or $40 \mathrm{mg} /$ day. Abbreviation: $\mathrm{AE}$, adverse event. 

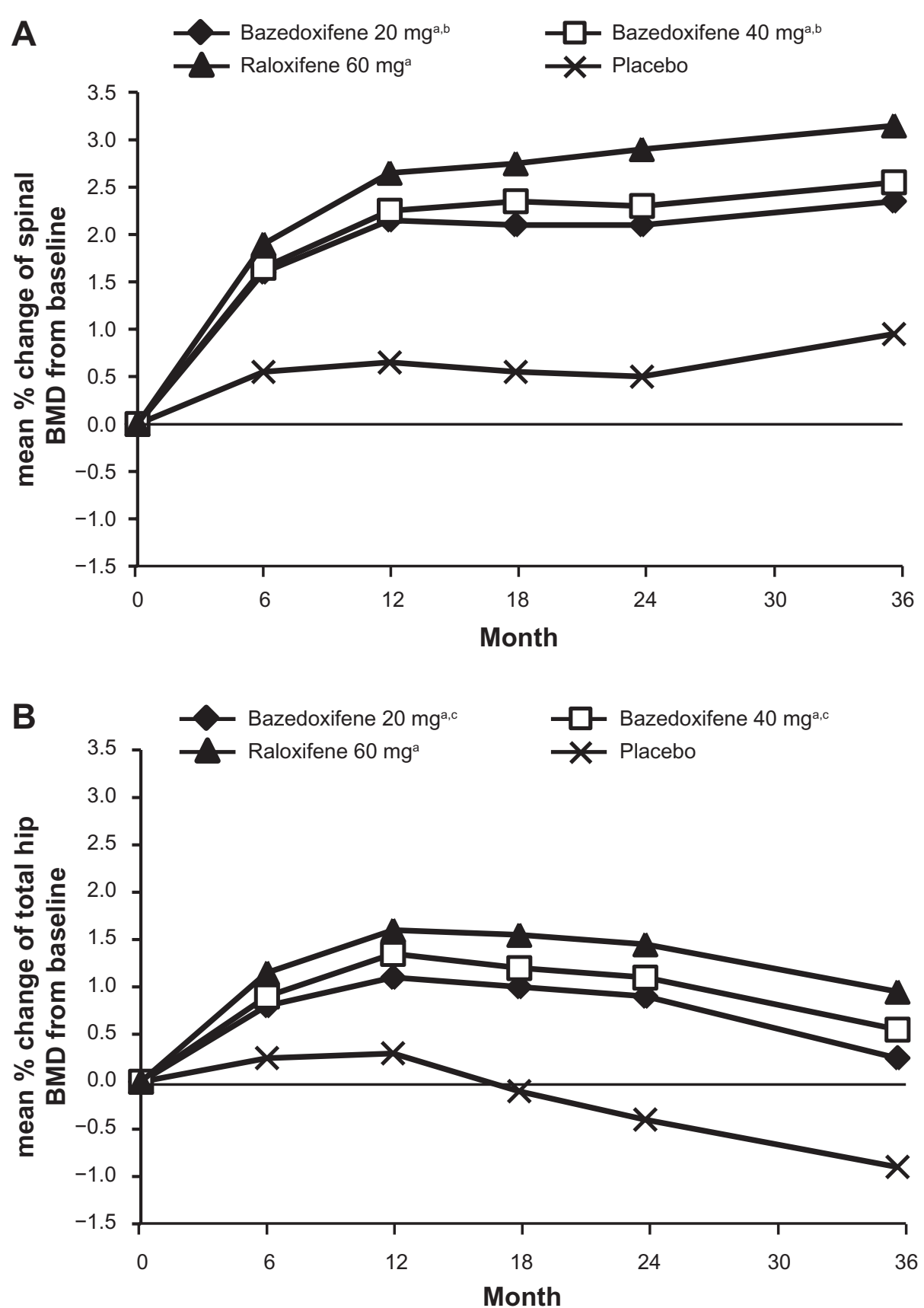

Figure 2 Effects of bazedoxifene on the lumbar spine and hip BMD. (A) Mean percent changes from baseline in the lumbar spine ( $\left.L_{1}-L_{4}\right) B M D$. (B) Mean percent changes from baseline in the total hip BMD.

Notes: ${ }^{a} P<0.00$ I vs placebo at each time point; ${ }^{b} P<0.05$ vs raloxifene at each time point; ${ }^{c} P<0.0$ I vs raloxifene at each time point.

Adapted from Silverman SL, Christiansen C, Genant HK, et al. Efficacy of bazedoxifene in reducing new vertebral fracture risk in postmenopausal women with osteoporosis: Results from a 3-year, randomized, placebo-, and active-controlled clinical trial. J Bone Miner Res. 2008;23(I2):1923-1934, with permission from the American Society for Bone and Mineral Research. ${ }^{29}$

Abbreviation: BMD, bone mineral density.

placebo, bazedoxifene $20 \mathrm{mg}$ and $40 \mathrm{mg}$ and raloxifene $60 \mathrm{mg}$ reduced the risk of new vertebral fractures by $42 \%$, $37 \%$, and $42 \%$, respectively (Figure 3 ). ${ }^{29}$ There were no significant differences in the incidence of new vertebral fractures between the bazedoxifene and raloxifene treatment groups. The incidence of nonvertebral fractures with bazedoxifene $20 \mathrm{mg}(5.7 \%)$ and $40 \mathrm{mg}(5.6 \%)$ and raloxifene $60 \mathrm{mg}(5.9 \%)$ did not differ significantly from placebo (6.3\%, Figure 3). However, in a post hoc analysis of a subgroup of women at higher fracture risk (femoral neck $\mathrm{T}$ score $\leq-3.0$ and/or at least one moderate or severe vertebral fracture or multiple mild vertebral fractures; $n=1772$ ), bazedoxifene 


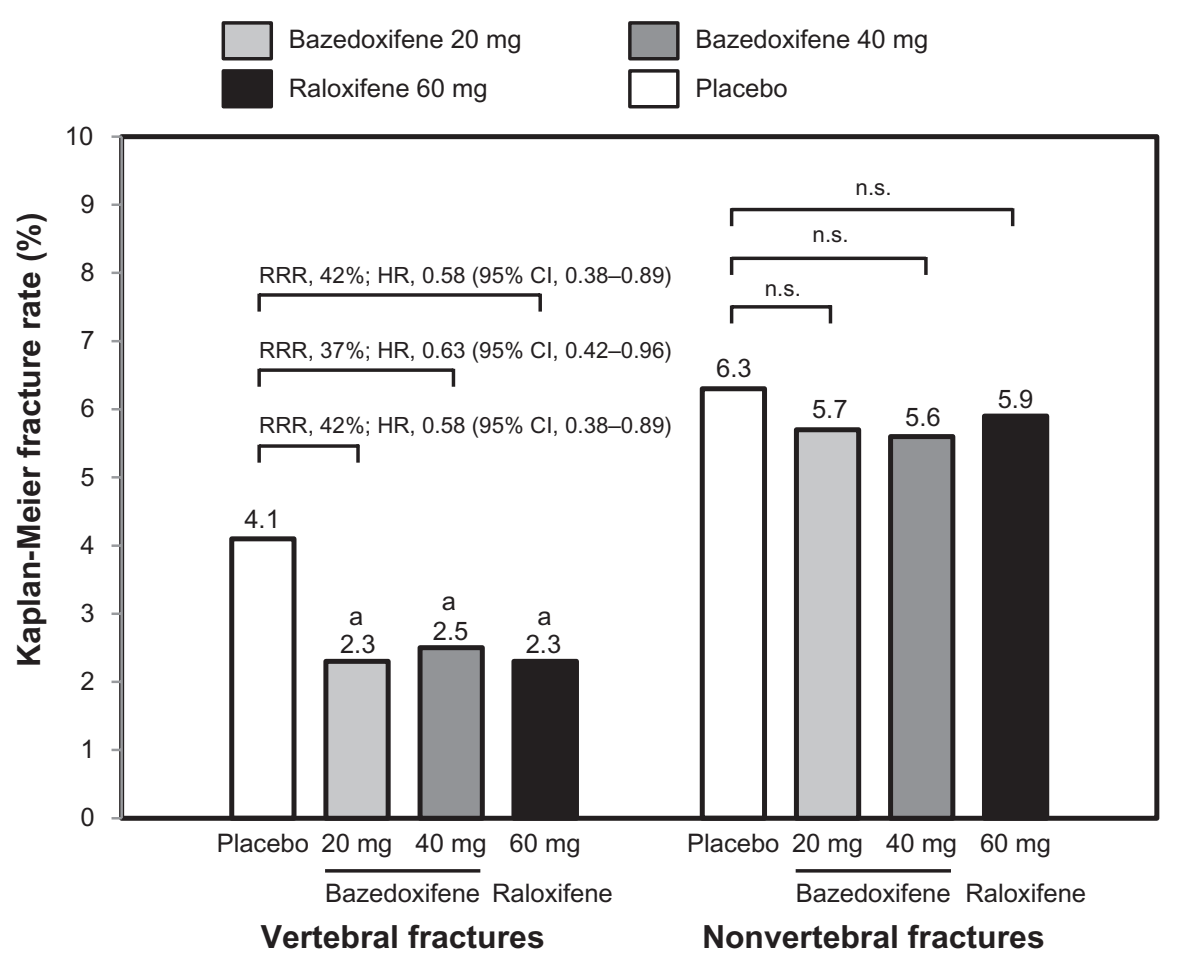

Figure 3 Effects of bazedoxifene on the incidence of new vertebral and nonvertebral fractures over 3 years in patients with postmenopausal osteoporosis. The numbers above the bars represent the incidence of fracture (\%) in each group.

Note: ${ }^{a} P<0.05$ vs placebo.

Adapted from Silverman SL, Christiansen C, Genant HK, et al. Efficacy of bazedoxifene in reducing new vertebral fracture risk in postmenopausal women with osteoporosis: Results from a 3-year, randomized, placebo-, and active-controlled clinical trial. J Bone Miner Res. 2008;23(I2):1923-I934, with permission from the American Society for Bone and Mineral Research. ${ }^{29}$

Abbreviations: $\mathrm{RRR}$, relative risk reduction; $\mathrm{HR}$, hazard ratio; $\mathrm{Cl}$, confidence interval; ns, not significant.

$20 \mathrm{mg}$ showed $50 \%$ and $44 \%$ reductions in nonvertebral fracture risk relative to placebo $(P=0.02)$ and raloxifene $60 \mathrm{mg}(P=0.05)$, respectively (Figure 4$)$. A similar reduction in nonvertebral fracture incidence was observed with bazedoxifene $40 \mathrm{mg}$, but the difference was not statistically significant (Figure 4).

An independent re-evaluation of fracture data from the Phase III study was performed using the Fracture Risk Assessment Tool $\left(\right.$ FRAX $\left.^{\circledR}\right)$ algorithm developed by the World Health Organization to estimate 10-year fracture risk. ${ }^{30,31}$ In patients with a 10 -year fracture risk $>6.9 \%$, bazedoxifene was associated with a significant decrease in risk of morphometric vertebral fractures. Moreover, in patients with 10-year fracture probabilities at or above $16 \%$, bazedoxifene was associated with a significant decrease in risk of all clinical fractures. ${ }^{31}$

In the 3-year Phase III trial, bazedoxifene $20 \mathrm{mg}$ and $40 \mathrm{mg}$ doses were well tolerated. The incidences of adverse events, serious adverse events, discontinuations because of adverse events, and deaths in the bazedoxifene groups were generally similar to those in the placebo group (Table 1). ${ }^{29}$ The most common adverse events were abdominal pain, accidental injury, arthralgia, back pain, flu syndrome, headache, hypertension, infection, and pain. The incidences of vasodilatation (hot flushes) and leg cramps were similar among the bazedoxifene and raloxifene treatment groups and significantly higher than those in the placebo group (Table 1). Most cases of vasodilatation were mild to moderate in severity and did not lead to discontinuation of therapy. The overall frequencies of cardiovascular events and stroke were low, and evenly distributed among the groups. The incidence of venous thromboembolic events (deep vein thrombosis and/or pulmonary embolism) was higher in the active treatment groups than in the placebo group, primarily because of an increased incidence of deep vein thrombosis, although the overall incidence of venous thromboembolic events in the active treatment groups was very low $(<1 \%$, Table 1). ${ }^{29}$ There was no significant difference in the incidence of venous thromboembolic events among the bazedoxifene and raloxifene treatment groups.

\section{Breast and endometrial safety}

Breast and endometrial safety is an important issue in the clinical development of new SERMs. Special attention was 


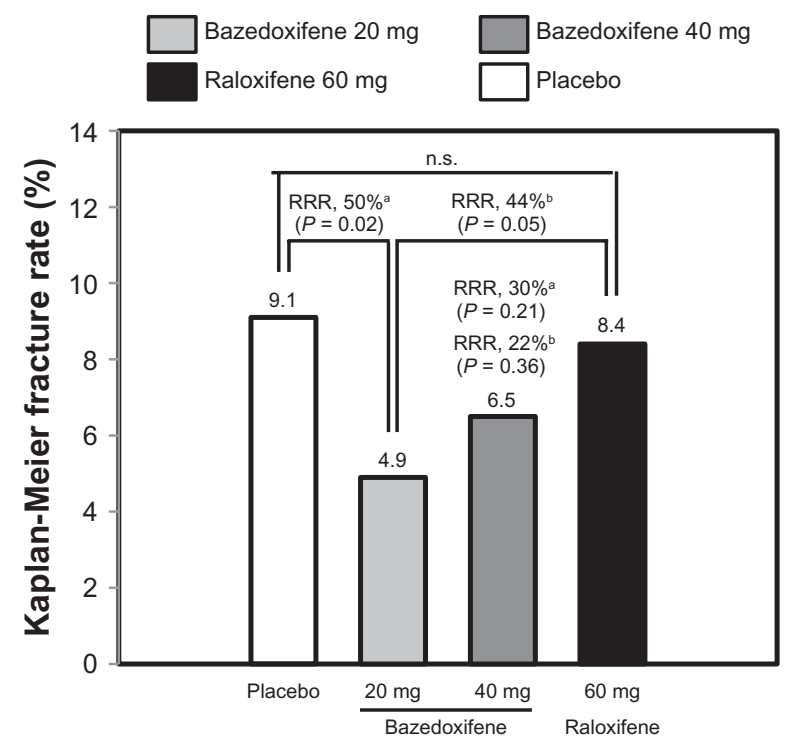

Figure $\mathbf{4}$ Incidence of nonvertebral fractures in subjects at a higher risk for fracture. The higher-risk subgroup was defined as a femoral neck $T$ score of $\leq-3.0$ and/ or $\geq$ I moderate or severe vertebral fractures or multiple mild vertebral fractures $(n=1772)$. The numbers above the bars represent the incidence of fracture (\%) in each group over 3 years.

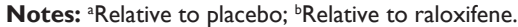

Adapted from Silverman SL, Christiansen C, Genant HK, et al. Efficacy of bazedoxifene in reducing new vertebral fracture risk in postmenopausal women with osteoporosis: Results from a 3-year, randomized, placebo-, and active-controlled clinical trial.J Bone Miner Res. 2008;23(12):1923-1934, with permission from the American Society for Bone and Mineral Research. ${ }^{29}$

Abbreviations: RRR, relative risk reduction; ns, not significant.

paid to evaluation of the reproductive tract and breast safety in the Phase III studies of bazedoxifene. ${ }^{32}$

In the 2-year Phase III trial, bazedoxifene was not associated with a significant change from baseline in mean endometrial thickness compared with placebo. There was no consensus diagnosis of endometrial hyperplasia or malignancy in the bazedoxifene and raloxifene groups (Table 1). There were no significant differences among the groups in the change from baseline in ovarian volume, number or size of ovarian cysts, or incidence of ovarian cancer. Reports of breast pain and breast cancer were low, and evenly distributed among the groups. ${ }^{28,33}$

In the 3-year Phase III trial, there were no significant changes in the mean endometrial thickness from baseline or in the incidence of endometrial hyperplasia and endometrial carcinoma among the groups (Table 1). ${ }^{29,34}$ There were no clinically important changes from baseline in number or size of ovarian cysts among the groups. No significant difference was reported in incidence of breast cancer among the groups. There was a significantly lower incidence of fibrocystic breast disease for bazedoxifene compared with raloxifene. Mammogram analyses after 24 months of therapy revealed that the mean percent changes in breast density from baseline were low and did not differ significantly among the groups. ${ }^{35}$ In the 2-year extension study, bazedoxifene showed no evidence of endometrial or breast stimulation over 5 years of therapy, consistent with findings at 3 years. Fewer cases of endometrial carcinoma were reported in the bazedoxifene group compared with the placebo group. ${ }^{36}$

\section{Bazedoxifene-conjugated estrogen combination therapy}

To achieve an ideal balance of estrogen receptor agonist and antagonist activities for optimal menopausal therapy, a novel approach of partnering a SERM with estrogens, designated the tissue-selective estrogen complex, has recently been investigated. Preclinical studies revealed that bazedoxifene antagonized estrogen-induced uterine and mammary gland stimulation more effectively than other SERMs, ie, raloxifene and lasofoxifene. ${ }^{37,38} \mathrm{~A}$ randomized, double-blind, placebo-controlled Phase III trial in postmenopausal women $(n=3397)$ examined the effect of bazedoxifene 10, 20, or $40 \mathrm{mg}$ combined with conjugated estrogens $0.625 \mathrm{mg}$ or $0.45 \mathrm{mg}$ on bone and endometrium as the primary endpoint. ${ }^{39-43}$ In this trial, the bazedoxifene-conjugated estrogen combination therapy group showed a statistically significant increase in bone mineral density and a decrease in bone turnover markers compared with those on placebo. ${ }^{42}$ In addition to the favorable effects on bone, bazedoxifeneconjugated estrogen therapy significantly reduced the frequency and severity of hot flushes and improved vulvarvaginal atrophy and its symptoms compared with placebo, with a good tolerability profile..$^{39-41}$

\section{Place of bazedoxifene in management of postmenopausal osteoporosis}

To date, several different types of drugs have been approved for the treatment of osteoporosis. Among them, bisphosphonates are generally considered as first-line therapy for most patients with osteoporosis. Many studies have shown that bisphosphonates increase the bone mineral density and reduce the incidence of fractures in patients with osteoporosis. ${ }^{44-46}$ However, upper gastrointestinal tract adverse effects, such as nausea, dyspepsia, abdominal pain, and esophagitis, are common with the use of oral bisphosphonates, resulting in discontinuation of treatment. ${ }^{46-48}$ In addition, long-term bisphosphonate therapy is associated with osteonecrosis of the jaw, defined as exposed nonviable jaw bone, and resistant to treatment. ${ }^{46-50}$ 
Hormone replacement therapy was widely recommended for treatment of osteoporosis, as well as for relief of menopausal symptoms. ${ }^{7,8}$ However, a large clinical trial revealed that long-term use of hormone replacement therapy increased the risks of breast cancer and stroke. ${ }^{9}$ Consequently, hormone replacement therapy is not usually recommended as a first-line therapy for long-term prevention of osteoporosis in women.

Teriparatide, as a recombinant human parathyroid hormone (PTH1-34), is an anabolic agent that stimulates bone formation and has the potential to improve skeletal microarchitecture. It has been demonstrated that teriparatide increases bone mineral density and significantly reduces fracture risk. ${ }^{51-53}$ However, the use of teriparatide is limited to patients with severe osteoporosis, because it is administered by daily subcutaneous injection and is much more expensive than other drugs used for osteoporosis.

Raloxifene is the first SERM approved for the prevention and treatment of postmenopausal osteoporosis. Raloxifene has been shown to increase bone mineral density and reduce the risk of vertebral fracture. ${ }^{14-16}$ In addition to its favorable effects on bone, raloxifene reduces the risk of invasive breast cancer and decreases low-density lipoprotein cholesterol levels. ${ }^{14-16,54,55}$ The adverse effects of raloxifene treatment are an increased risk of venous thromboembolism and an increased incidence of vasomotor symptoms. ${ }^{15,16}$ Owing to the limited clinical data for fracture compared with those of bisphosphonates and the potential for serious adverse events, raloxifene is generally considered as a second-line therapy for women with postmenopausal osteoporosis. ${ }^{6,56,57}$

Bazedoxifene also showed an increase in bone mineral density and a reduction of risk of vertebral fractures in osteoporotic patients, without stimulating the endometrium or breast. ${ }^{28,29}$ The incidence of nonvertebral fractures in women at a higher fracture risk was also reduced by bazedoxifene compared with placebo or raloxifene. ${ }^{29}$ Bazedoxifene was shown to inhibit conjugated estrogen-induced responses in the uterine and mammary glands in animal models more effectively than other SERMs. ${ }^{37,38}$ Taking advantage of the favorable effects of bazedoxifene on the breast and endometrium, the tissue-selective estrogen complex that pairs bazedoxifene with conjugated estrogens is currently under clinical evaluation for the treatment of osteoporosis and menopausal symptoms.

\section{Conclusion}

Two global Phase III trials have shown the effectiveness of bazedoxifene in the prevention and treatment of postmenopausal osteoporosis without stimulating the endometrium and breast. Although bazedoxifene is a promising new therapy for patients with osteoporosis, further clinical investigations of long-term treatment with this SERM are needed to evaluate the prevention of osteoporotic fractures, breast cancers, endometrial cancers, and cardiovascular events. When treating patients with osteoporosis, estrogens and SERMs have effects not only on bone metabolism, but also on the breast, endometrium, and lipid metabolism. Before starting treatment, a riskbenefit assessment should be performed for each patient with osteoporosis.

\section{Disclosure}

The authors report no conflicts of interest in this work.

\section{References}

1. Raisz LG. Pathogenesis of osteoporosis: concepts, conflicts, and prospects. J Clin Invest. 2005;115(12):3318-3325.

2. Sambrook P, Cooper C. Osteoporosis. Lancet. 2006;367(9527): 2010-2018.

3. Cauley JA, Thompson DE, Ensrud KC, Scott JC. Risk of mortality following clinical fractures. Osteoporos Int. 2000;11(7):556-561.

4. Bianchi ML, Orsini MR, Saraifoger S, Ortolani S, Radaelli G, Betti S. Quality of life in post-menopausal osteoporosis. Health Qual Life Outcomes. 2005;3:78.

5. Siris ES, Brenneman SK, Barrett-Connor E, et al. The effect of age and bone mineral density on the absolute, excess, and relative risk of fracture in postmenopausal women aged 50-99: results from the National Osteoporosis Risk Assessment (NORA). Osteoporos Int. 2006; 17(4):565-574.

6. Lewiecki EM. Current and emerging pharmacologic therapies for the management of postmenopausal osteoporosis. J Womens Health. 2009;18(10):1615-1626.

7. Cauley JA, Seeley DG, Ensrud K, Ettinger B, Black D, Cummings SR. Estrogen replacement therapy and fractures in older women. Study of Osteoporotic Fractures Research Group. Ann Intern Med. 1995; 122(1):9-16.

8. Michaëlsson K, Baron JA, Johnell O, Persson I, Ljunghall S. Variation in the efficacy of hormone replacement therapy in the prevention of hip fracture. Swedish Hip Fracture Study Group. Osteoporos Int. 1998; 8(6):540-546.

9. Rossouw JE, Anderson GL, Prentice RL, et al; Writing Group for the Women's Health Initiative Investigators. Risks and benefits of estrogen plus progestin in healthy postmenopausal women: principal results From the Women's Health Initiative randomized controlled trial. JAMA. 2002; 288(3):321-323.

10. Cuzick J, Baum M. Tamoxifen and contralateral breast cancer. Lancet. 1985;2(8449):282.

11. Fisher B, Costantino J, Redmond C, et al. A randomized clinical trial evaluating tamoxifen in the treatment of patients with node-negative breast cancer who have estrogen-receptor-positive tumors. $N$ Engl $J$ Med. 1989;320(8):479-484.

12. Love RR, Mazess RB, Barden HS, et al. Effects of tamoxifen on bone mineral density in postmenopausal women with breast cancer. $N$ Engl J Med. 1992;326(13):852-856.

13. Fisher B, Costantino JP, Redmond CK, Fisher ER, Wickerham DL, Cronin WM. Endometrial cancer in tamoxifen-treated breast cancer patients: findings from the National Surgical Adjuvant Breast and Bowel Project (NSABP) B-14. J Natl Cancer Inst. 1994;86(7): $527-537$. 
14. Black LJ, Sato M, Rowley ER, et al. Raloxifene (LY139481 HCI) prevents bone loss and reduces serum cholesterol without causing uterine hypertrophy in ovariectomized rats. J Clin Invest. 1994;93(1): 63-69.

15. Ettinger B, Black DM, Mitlak BH, et al. Reduction of vertebral fracture risk in postmenopausal women with osteoporosis treated with raloxifene: results from a 3-year randomized clinical trial. Multiple Outcomes of Raloxifene Evaluation (MORE) Investigators. JAMA. 1999;282(7):637-645.

16. Delmas PD, Ensrud KE, Adachi JD, et al; Mulitple Outcomes of Raloxifene Evaluation Investigators. Efficacy of raloxifene on vertebral fracture risk reduction in postmenopausal women with osteoporosis: four-year results from a randomized clinical trial. J Clin Endocrinol Metab. 2002;87(8):3609-3617.

17. Gruber C, Gruber D. Bazedoxifene (Wyeth). Curr Opin Investig Drugs. 2004;5(10):1086-1093.

18. Gennari L, Merlotti D, De Paola V, Martini G, Nuti R. Bazedoxifene for the prevention of postmenopausal osteoporosis. Ther Clin Risk Manag. 2008;4(6):1229-1242.

19. Miller CP, Collini MD, Tran BD, et al. Design, synthesis, and preclinical characterization of novel, highly selective indole estrogens. $\mathrm{J} \mathrm{Med}$ Chem. 2001;44(11):1654-1657.

20. Komm, BS, Lyttle CR. Developing a SERM: stringent preclinical selection criteria leading to an acceptable candidate (WAY-140424) for clinical evaluation. Ann N Y Acad Sci. 2001;949:317-326.

21. Komm BS, Kharode YP, Bodine PV, Harris HA, Miller CP, Lyttle CR. Bazedoxifene acetate: a selective estrogen receptor modulator with improved selectivity. Endocrinology. 2005;146(9):3999-4008.

22. Peano BJ, Crabtree JS, Komm BS, Winneker RC, Harris HA. Effects of various selective estrogen receptor modulators with or without conjugated estrogens on mouse mammary gland. Endocrinol. 2009; 150(4):1897-1903

23. Ermer J, McKeand W, Sullivan P, et al. Bazedoxifene acetate dose proportionality in healthy, postmenopausal women. Clin Pharmacol Ther. 2003;73(2):46.

24. Chandrasekaran A, McKeand WE, Sullivan P, DeMaio W, Stoltz R, Scatina J. Metabolic disposition of $\left[{ }^{14} \mathrm{C}\right]$ bazedoxifene in healthy postmenopausal women. Drug Metab Dispos. 2009;37(6): 1219-1225.

25. Ronkin S, Clarke L. TSE-424, a novel tissue selective estrogen, reduces biochemical indices of bone metabolism in a dose related fashion. J Bone Miner Res. 2001;16(Suppl 1):S413.

26. Ronkin S, Northington R, Baracat E, et al. Endometrial effects of bazedoxifene acetate, a novel selective estrogen receptor modulator, in postmenopausal women. Obstet Gynecol. 2005;105(6):1397-1404.

27. Boudes P, Ronkin S, Korner S, et al. Effects of bazedoxifene (TSE-424), a novel tissue selective estrogen receptor modulator (SERM), on the incidence of breast pain. Osteoporos Int. 2003;14 (Suppl 7):S14.

28. Miller PD, Chines AA, Christiansen C, et al. Effects of bazedoxifene on BMD and bone turnover in postmenopausal women: 2-yr results of a randomized, double-blind, placebo-, and active-controlled study. J Bone Miner Res. 2008;23(4):525-535.

29. Silverman SL, Christiansen C, Genant HK, et al. Efficacy of bazedoxifene in reducing new vertebral fracture risk in postmenopausal women with osteoporosis: results from a 3-year, randomized, placebo-, and active-controlled clinical trial. J Bone Miner Res. 2008;23(12): 1923-1934.

30. Kanis JA, Johnell O, Oden A, Johansson H, McCloskey E. FRAX and the assessment of fracture probability in men and women from the UK. Osteoporos Int. 2008;19(4):385-397.

31. Kanis JA, Johansson H, Oden A, McCloskey EV. Bazedoxifene reduces vertebral and clinical fractures in postmenopausal women at high risk assessed with FRAX. Bone. 2009;44(6):1049-1054.

32. de Villiers TJ. Bazedoxifene: a novel selective estrogen receptor modulator for postmenopausal osteoporosis. Climacteric. 2010;13(3): 210-218.
33. Pinkerton JV, Archer DF, Utian WH, et al. Bazedoxifene effects on the reproductive tract in postmenopausal women at risk for osteoporosis. Menopause. 2009;16(6):1102-1108.

34. Archer DF, Pinkerton JV, Utian WH, et al. Bazedoxifene, a selective estrogen receptor modulator: effects on the endometrium, ovaries, and breast from a randomized controlled trial in osteoporotic postmenopausal women. Menopause. 2009;16(6):1109-1115.

35. Harvey JA, Holm MK, Ranganath R, Guse PA, Trott EA, Helzner E. The effects of bazedozifene on mammographic breast density in postmenopausal women with osteoporosis. Menopause. 2009;16(6):1193-1196.

36. de Villiers TJ, Chines AA, Palacios S, et al. Safety and tolerability of bazedoxifene in postmenopausal women with osteoporosis: results of a 5-year, randomized, placebo-controlled phase 3 trial. Osteoporos Int. 2011;22(2):567-576.

37. Kharode Y, Bodine PV, Miller CP, Lyttle CR, Komm BS. The pairing of a selective estrogen receptor modulator, bazedoxifene, with conjugated estrogens as a new paradigm for the treatment of menopausal symptoms and osteoporosis prevention. Endocrinology. 2008;149(12):6084-6091.

38. Peano BJ, Crabtree JS, Komm BS, Winneker RC, Harris HA. Effects of various selective estrogen receptor modulators with or without conjugated estrogens on mouse mammary gland. Endocrinology. 2009;150(4):1897-1903.

39. Pickar JH, Yeh IT, Bachmann G, Speroff L. Endometrial effects of a tissue selective estrogen complex containing bazedoxifene/conjugated estrogens as a menopausal therapy. Fertil Steril. 2009;92(3):1018-1024.

40. Lobo RA, Pinkerton JV, Gass ML, et al. Evaluation of bazedoxifene/ conjugated estrogens for the treatment of menopausal symptoms and effects on metabolic parameters and overall safety profile. Fertil Steril. 2009;92(3):1025-1038.

41. Archer DF, Lewis V, Carr BR, Olivier S, Pickar JH. Bazedoxifene/ conjugated estrogens (BZA/CE): incidence of uterine bleeding in postmenopausal women. Fertil Steril. 2009;92(3):1039-1044.

42. Lindsay R, Gallagher JC, Kagan R, Pickar JH, Constantine G. Efficacy of tissue-selective estrogen complex of bazedoxifene/conjugated estrogens for osteoporosis prevention in at-risk postmenopausal women. Fertil Steril. 2009;92(3):1045-1052.

43. Lindsay R. Preventing osteoporosis with a tissue selective estrogen complex (TSEC) containing bazedoxifene/conjugated estrogens (BZA/ CE). Osteoporos Int. 2011;22(2):447-451.

44. Black DM, Cummings SR, Karpf DB, et al. Randomised trial of effect of alendronate on risk of fracture in women with existing vertebral fractures. Fracture Intervention Trial Research Group. Lancet. 1996; 348(9041):1535-1541.

45. McClung MR, Geusens P, Miller PD, et al. Effect of risedronate on the risk of hip fracture in elderly women. Hip Intervention Program Study Group. N Engl J Med. 2001;344(5):333-340.

46. Favus MJ. Bisphosphonates for osteoporosis. N Engl J Med. 2011; 363(21):2027-2035.

47. Papapetrou PD. Bisphosphonate-associated adverse events. Hormones. 2009;8(2):96-110.

48. Kennel KA, Drake MT. Adverse effects of bisphosphonates: implications for osteoporosis management. Mayo Clin Proc. 2009;84(7):632-638.

49. Ruggiero SL, Mehrotra B. Bisphosphonate-related osteonecrosis of the jaw: diagnosis, prevention, and management. Annu Rev Med. 2009;60: 85-96.

50. Kawai M, Mödder UI, Khosla S, Rosen CJ. Emerging therapeutic opportunities for skeletal restoration. Nat Rev Drug Discov. 2011;10(2): 141-156.

51. Neer RM, Arnaud CD, Zanchetta JR, et al. Effect of parathyroid hormone (1-34) on fractures and bone mineral density in postmenopausal women with osteoporosis. N Engl J Med. 2001;344(19):1434-1441.

52. Body JJ, Gaich GA, Scheele WH, et al. A randomized double-blind trial to compare the efficacy of teriparatide [recombinant human parathyroid hormone (1-34)] with alendronate in postmenopausal women with osteoporosis. J Clin Endocrinol Metab. 2002;87(10) 4528-4535. 
53. Hodsman AB, Bauer DC, Dempster DW, et al. Parathyroid hormone and teriparatide for the treatment of osteoporosis: a review of the evidence and suggested guidelines for its use. Endocr Rev. 2005;26(5): 688-703.

54. Barrett-Connor E, Mosca L, Collins P, et al; Raloxifene Use for The Heart (RUTH) Trial Investigators. Effects of raloxifene on cardiovascular events and breast cancer in postmenopausal women. N Engl J Med. 2006;355(2):125-137.

55. Vogel VG, Costantino JP, Wickerham DL, et al; National Surgical Adjuvant Breast and Bowel Project (NSABP). Effects of tamoxifen vs raloxifene on the risk of developing invasive breast cancer and other disease outcomes: The NSABP Study of Tamoxifen and Raloxifene (STAR) P-2 trial. JAMA. 2006;295(23):2727-2741.
56. Bushardt RL, Turner JL, Ragucci KR, Askins DG Jr. Non-estrogen treatments for osteoporosis: an evidence-based review. JAAPA. 2006; 19(12):25-30.

57. Paracios S. Efficacy and safety of bazedoxifene, a novel selective estrogen receptor modulator for the prevention and treatment of postmenopausal osteoporosis. Curr Med Res Opin. 2010;26(7):1553-1563.

\section{Publish your work in this journal}

Clinical Interventions in Aging is an international, peer-reviewed journal focusing on evidence-based reports on the value or lack thereof of treatments intended to prevent or delay the onset of maladaptive correlates of aging in human beings. This journal is indexed on PubMed Central, MedLine, the American Chemical Society's 'Chemical
Abstracts Service' (CAS), Scopus and the Elsevier Bibliographic databases. The manuscript management system is completely online and includes a very quick and fair peer-review system, which is all easy to use. Visit http://www.dovepress.com/testimonials.php to read real quotes from published authors. 